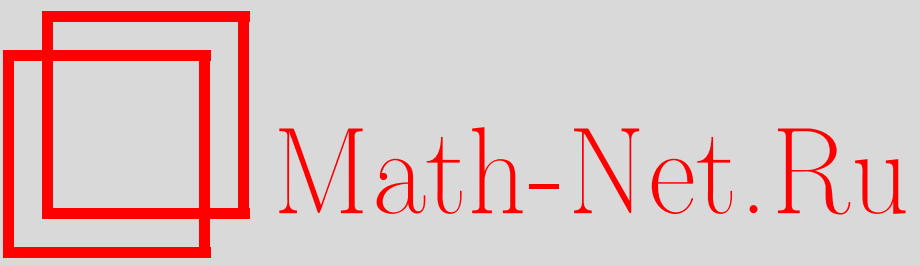

М.-М. Деза, М. Дютур, М. И. Штогрин, Эллиптические полициклы с дырами, УМH, 2005, том 60, выпуск 2, 157-158

DOI: https://doi.org/10.4213/rm1413

Использование Общероссийского математического портала Math-Net.Ru подразумевает, что вы прочитали и согласны с пользовательским соглашением

http://www . mathnet.ru/rus/agreement

Параметры загрузки:

IP: 54.162 .127 .20

26 апреля 2023 г., 06:55:23 


\title{
ЭЛЛИПТИЧЕСКИЕ ПОЛИЦИКЛЫ С ДЫРАМИ
}

\author{
М. ДЕЗА, М. Дютур, М. И. Штогрин
}

Рассмотрим произвольный 2-связный локально конечньй плоский граф̆ $G$. Пусть (i) степени всех вершин данного граффа не превьшают $q$, где $q$ фиксировано, $q \geqslant 3$.

Пусть, далее, множество всех внутренних граней плоского графа $G$ разбивается на два подмножества $F_{1}$ и $F_{2}$, для которых выполнены следующие три дополнительные условия:

(ii) все грани из множества $F_{1}$ являются $r$-уголшниками, где $r$ фиксировано, $r \geqslant 3$;

(iii) все грани из множества $F_{2}$ попарно не пересекаются друг с другом; более того, никакая грань из множества $F_{2}$ не пересекается с внешней гранью плоского графа $G$;

(iv) каждая вершина граф̆ $G$, степень которой меньше $q$ (она не меньше 2 в силу 2-связности), принадлежит либо грани из множества $F_{2}$, либо же внешней грани графа $G$.

Тогда плоский графф $G$ с присоединенными к нему гранями из множества $F_{1}$ назовем $(r, q)$-noлициклом с дырами и обозначим через $P=P\left(G, F_{1}\right)$. Грани из множеств $F_{1}$ и $F_{2}=F_{2}\left(F_{1}\right)$ назовем соответственно гранями и дырами полицикла $P$. Полицикл $P$ имеет два типа ребер: внутреннее ребро принадлежит двум граням полицикла, граничное ребро принадлежит одной грани полицикла. Все граничные ребра составляют границу полицикла $P$. Внутреннее ребро назовем скв озньцм, если оба его конца лежат на границе полицикла $P=P\left(G, F_{1}\right)$.

Полицикл назовем әлементарным, если выполняется следующая альтернатива: либо у него нет сквозных ребер - он простой, либо у него есть сквозные ребра, но при разрезании сразу по всем сквозным ребрам полицикл остается связным - он самосклеенный.

Разрезанный по всем сквозньм ребрам полицикл с дырами распадется на компоненты связности - простые элементарные полициклы. Неразрезанный полицикл остается связньм; некоторые его элементарные слагаемые (см. [1]) могут быть самосклеены.

Ниже мы даем полное перечисление элементарных $(r, q)$-полициклов с дырами для всех әллиптических параметров $(r, q)$, т.е. $(r, q)=(3,3),(3,4),(4,3),(3,5),(5,3)$. Общее число дыр полицикла, обозначим его через $t$, предполагается произвольным, $0 \leqslant t \leqslant \infty$.

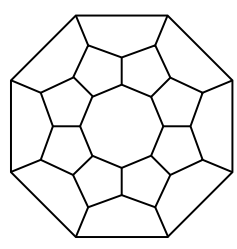

Рис. 1. $F_{16}$

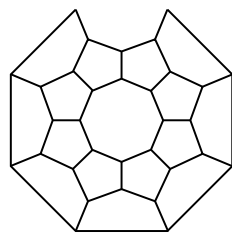

Рис. 2. $E_{13}^{*}$

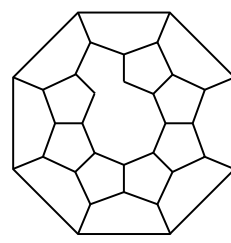

Рис. 3. $E_{13}^{* *}$

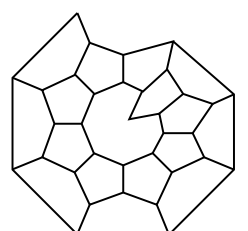

Рис. 4. $E_{14}^{*}$

Случай 1 . При $t=0$ все элементарные $(5,3)$-полициклы найдены в [1; табл. 1$]$. При $t=1$ имеются четьре серии элементарных $(5,3)$-полициклов - одна серия простых $(5,3)$-полициклов $F_{2 n+4}$, рис. 1 , и три серии самосклеенных $(5,3)$-полициклов $E_{2 n+1}^{*}$ (дыра $(n+2)$-угольна), $E_{2 n+1}^{* *}\left(\right.$ дыра $(n+5)$-угольна) и $E_{2 n}^{*}, n \in \mathbb{N}$, см. рис. 2,3 и 4 соответственно; на рис. 2 и 3 внешняя грань и дыра поменялись ролями: самосклеенные полициклы $E_{2 n+1}^{*}$ и $E_{2 n+1}^{* *}$ получаются при одном и том же отождествлении открытых (в смысле [1]) ребер (с концами степени 2) простого полицикла $E_{2 n+1}$, взятого из [1; табл. 1], но у них разные укладки на плоскости (чего не было у обычных полициклов [1]-[3]). Имеются пять индивидуальных элементарных самосклеенных $(5,3)$-полициклов: $C_{1}^{*}, C_{2}^{*}$ (дыра 4 -угольна), $C_{2}^{* *}$ (дыра 6 -угольна), $C_{3}^{*}$ (дыра 3 -угольна) $)^{1}, C_{3}^{* *}$ (дыра 7-угольна $)^{2}$. Они получаются из простых полициклов $C_{1}, C_{2}, C_{3}$, взятых из [1; табл. 1$]$, при

Работа выполнена при финансовой поддержке Российского фонда фундаментальных исследований (грант 05-01-00170), Фонда поддержки ведущих научных школ (грант НШ-2185.2003.1) и Программы ОМН РАН "Современные проблемы теоретической математики".

${ }^{1}$ Имеется (не)счетное число (бес)конечных $(5,3)$-полициклов с элементарным слагаемшім $C_{3}^{*}$.

2 Число конечных $(5,3)$-полициклов с элементарным слагаемьм $C_{3}^{* *}$ счетно. Бесконечных нет: локально конечньй граф̆ имеет лишь конечное число вершин и ребер в дыре полицикла $C_{3}^{* *}$. 
отождествлении их открытых ребер (с концами степени 2$)$. При $t \geqslant 2$ элементарных $(5,3)$-полициклов не существует.

Случай 2. При $t=0$ все элементарные $(3,5)$-полициклы найдены в [1; табл. 2]. При $t=1$ имеются четьре серии элементарных $(3,5)$-полициклов - одна серия простых $(3,5)$-полициклов $f_{2 n+4}$, рис. 5 , и три серии самосклеенных $(3,5)$-полициклов $e_{2 n+3}^{*}$ (дыра $(n+2)$-угольна), $e_{2 n+3}^{* *}$ (дыра $(n+3)$-угольна) и $e_{2 n+2}^{*}, n \in \mathbb{N}$, см. рис. 6,7 и 8 . Один индивидуальньй элементарньй самосклеенный $(3,5)$-полицикл $b_{2}^{*}$ получается из простого полицикла $b_{2}$, взятого из $[1 ;$ табл. 2$]$, при отождествлении его сильно открытых (в смысле [1]) ребер (с концами степени 3 ). При $t \geqslant 2$ элементарных $(3,5)$-полициклов не существует.

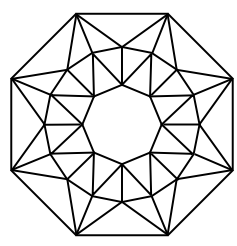

Рис. 5. $f_{16}$

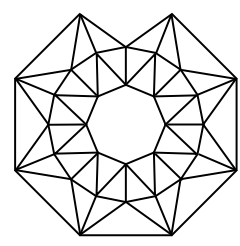

Рис. 6. $e_{15}^{*}$

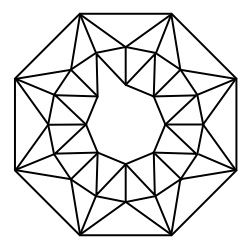

Рис. 7. $e_{15}^{* *}$

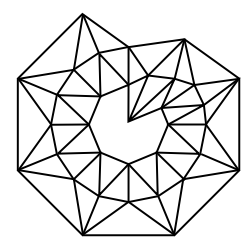

Рис. 8. $e_{16}^{*}$

Случай 3 . При $t=0$ имеются 4 элементарных $(4,3)$-полицикла, в их состав входят: пять граней куба; четыре грани куба, инцидентные с одним ребром; три грани куба с одной общей вершиной; одна грань куба. При $t \geqslant 1$ элементарных $(4,3)$-полициклов нет.

Случай 4 . При $t=0$ имеем 4 элементарных $(3,4)$-полицикла, в их состав входят: семь граней октаэдра; шесть граней октаэдра, инцидентных с одним ребром; четыре грани октаэдра с одной общей вершиной; одна грань октаэдра. При $t \geqslant 1$ элементарных $(3,4)$-полициклов нет.

Случай 5 . При $t=0$ существуют два элементарных $(3,3)$-полицикла, в их состав входят: три грани тетраэдра; одна грань тетраэдра. При $t \geqslant 1$ элементарных $(3,3)$-полициклов нет.

Теорема. В случаях 1-5 перечислены все әлементарные $(r, q)$-поличикль с дырами для всех әллиптических параметров $(r, q)$, m.е. $(r, q)=(3,3),(3,4),(4,3),(3,5),(5,3)$.

Доказательство теоремы сводится к обоснованию полноты списка ядер (см. [1]) полициклов.

Каждый элементарньй полицикл из вышеуказанных 8 серий является элементарным слагаемым лишь для себя самого, хотя $E_{2 n+1}^{*}, E_{2 n+1}^{* *}, F_{10}, e_{2 n+3}^{*}, e_{2 n+3}^{* *}, f_{6}$ расширяемы. Полициклы $F_{2 n+4}$ при $n \neq 3, E_{2 n}^{*}, f_{2 n+4}$ при $n \neq 1, e_{2 n+2}^{*}$ нерасширяемы. Дыры в полициклах $F_{10}, E_{7}^{*}$, $f_{6}, e_{5}^{*}$ и $C_{1}^{*}, b_{2}^{*}$ устранимы (каждую дыру можно заклеить своим ${ }^{3} r$-угольником).

Число дыр неэлементарных $(5,3)$ - и $(3,5)$-полициклов ничем не ограничено сверху. Число дыр $(4,3)$ - и $(3,4)$-полициклов не больше 1 . Неэлементарньй $(4,3)$-полицикл с одной дырой представляет собою боковую поверхность $m$-призмы, $m \geqslant 3$; он нерасширяем при $m=3$ и $m \geqslant 5$, собственныц й (см. [1]) при $m=4$ и гелицен (см. [1]) при $m=4+4 n, n \in \mathbb{N}$. Неэлементарный $(3,4)$-полицикл с одной дырой представляют собою боковую поверхность $m$-антипризмы, $m \geqslant 3$; он нерасширяем при $m \geqslant 4$, собственный при $m=3$ и гелицен при $m=3+3 n, n \in \mathbb{N}$. Все $(3,3)$-полициклы (их имеется всего лишь три) оказались без дыр.

\section{СПИСОК ЛИТЕРАТУРЫ}

[1] М. Деза, М.И. Штогрин // Труды МИАН. 2002. Т. 239. С. 127-145. [2] М. Деза, М.И. Штогрин // УМН. 1999. Т. 54. №6. С. 159-160. [3] М. Деза, М. И. Штогрин // УМH. 2000. T. 55. № 1. C. 179-180.

CNRS/ENS, Paris and Institute of Statistical Mathematics, Tokyo;

ENS, Paris and Hebrew University, Jerusalem;

Представлено В.М. Бухштабером

Математический институт им. В. А. Стеклова РАН

E-mail: Michel.Deza@ens.fr; Mathieu.Dutour@ens.fr; stogrin@mi.ras.ru

\footnotetext{
${ }^{3}$ Дыру полицикла $E_{7}^{* *}\left(e_{5}^{* *}\right)$ можно заклеить двумя пятиугольниками (треугольниками).
} 